\title{
赤痢菌の栄養要求に関する研究
}

\section{（II） ニコチン酸類似化合物の赤峲菌発育に及ぼす影響}

\author{
中山英男*1) - 元木義信 \\ 山口県衛生研究所（所長 芳野俊五博士）
}

[受付： 7 月 25 日・ 1960 年]

前報1 で述べた様に赤痢菌特に Sh. flexneri, Sh. boydii, Sh. sonnei 化属する菌株の多くはその発育に $\mathrm{NiA}^{* 22}$ を必要とする。一般に発育因子と化学構造上類 似している化合物㤁細菌の発育阻止作用を呈することの あるととは P A B A と Sulfonamide の関係が明らかに なつて以来 ${ }^{2}$ 広く知られるに至つた。 $\mathrm{NiA}$ 類似化合物の 3ち Pyridine-3-sulfonic acid は NiA の代謝拮抗物質已 乙て細菌の発育に阻止的化作用することが知られてい

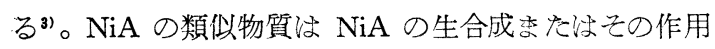
を阻止するととにより抗菌力を示すと考光られる。との ととより NiA を必要とする細菌即ち NiA の生合成過 程が不能な菌株に対しては $\mathrm{NiA}$ の生合成能力をもつ菌 株より以上にこれら類似化合物治強い抗菌力示すので はないかと考え一連の実験を行なつた。

供試した NiA 類似化合物としては 3 -Acetyl pyridine, Pyridine-3-sulfonic acid, $\alpha$-Picolinic acid 揖よび I N A H の 4 種である. 今回住 $\mathrm{NiA}$ 要求扢よび非要求性の赤㾐 菌株拉よび E. coli 1 株を被検菌としててれら類似化合 物の発育に招よ济す影響について検討した。との結果と れら類似化合物のうちで Pyridine-3-sulfonic acid のみが

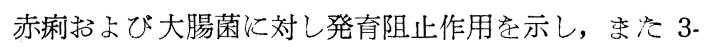

Acetyl pyridine は NiAの活性をある程度代用しうると の成績を得たので報告する。

尚本論の概要以第 116 回ビタミンB研究委員会の席上 で公表しだ。

\section{実験材料と方法}

使用菌株：赤㾥菌としての (1) NiA 要要とするもの として Sh. sonnei I に属する標準株, Strain 1196 抢よ び分離株を (2) NiA を必要とせず基礎培地のみでよく発 育する菌株の代表として Sh. flexneri 3a 飞属する 1 株 の分離菌をそれぞれ使用した。また大腸菌としては $E$. coli O-20標準株を用いた。こ㣗ら菌株は普通寒天斜面に $37^{\circ} \mathrm{C} 24$ 時間培養したものより接種菌を調製した。

試験用培地：Davis Mingioli の培地 ${ }^{5.6)}$ を改変したブ ドー糖, 無機アンモン, 無機塩類よりなる合成培地を使 用した。試験管中の培地浪最終 $5 \mathrm{cc}$ となる様に用いた。 培地調製の実際, 添加物の添加法, 菌発奇程度の測定等 はすべて前報1に準じて行つた。

供試 NiA 類似化合物 : 3-Acetyl pyridine, Pyridine3--sulfonic acid, $\boldsymbol{\alpha}$-Picolinic acid 招よびINAHの 4 種の化合物を使用した。前 3 者は N B C 製のもの, 後者 はイソニアジッドを用いた。供試化合物の化学構造は図 1 に示した。とれら法いずれも $10^{-2} \mathrm{M} / l$ の割に蒸水汪と かし $10 \mathrm{lb} 10$ 分間高圧隇菌し, 用にのぞんで隇菌水で最 終濃度の10倍になる様に稀釈しその $0.5 \mathrm{cc}$ あてを分注使 用した。 $\mathrm{NiA}, \mathrm{NAA}^{* 3)}$ 等もこれら化合物と同様化調製 した。

\section{実験成経}

〔 I] $\mathrm{NiA}$ 要求株飞刘する $\mathrm{NiA}$ 類似化合物の作用

1) Pyridine-3-sulfonic acid $の$ 作用: Sh. sonnei $I$ 分 離株江対する Pyridine-3-sulfonic acid の作用以図 2 に 示した。本菌株は $\mathrm{NiA}$ 委た注 $\mathrm{NAA}$ 基礎培地添加

NAKAYAMA Hideo and MOTOKI Yoshinobu: Nutritional Studies in Genus Shigella. (II) Growth Activities of Niacin Analogous to the Certain Strains of Sh. Alexneri, Sh. sonnei and Escherichia coli. Yamaguchi Prefectural Research Institute of Health, Yamaguchi, Japan. -Jap. J. of Bact., 16 (2), 98-102, 1961.

*1) 山口県立女子短期大学, 山口県立医科大学微生物 学教室

*2) $\mathrm{NiA}=$ Nicotinic acid

*3) $\mathrm{NAA}=$ Nicotinamide 
図 1 被検化合物

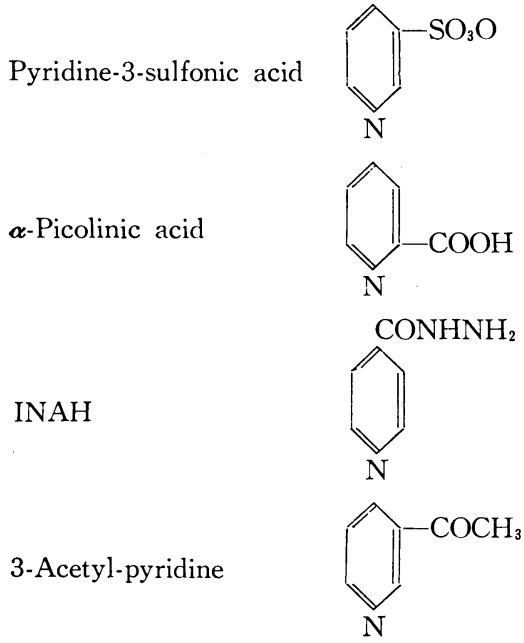

図 2 Sh. sonnei (I) 分蒦株の Pyridine-3-sulfonic acid による発育阻止と NiA, NAA 添加の影響 24 hours Incubation

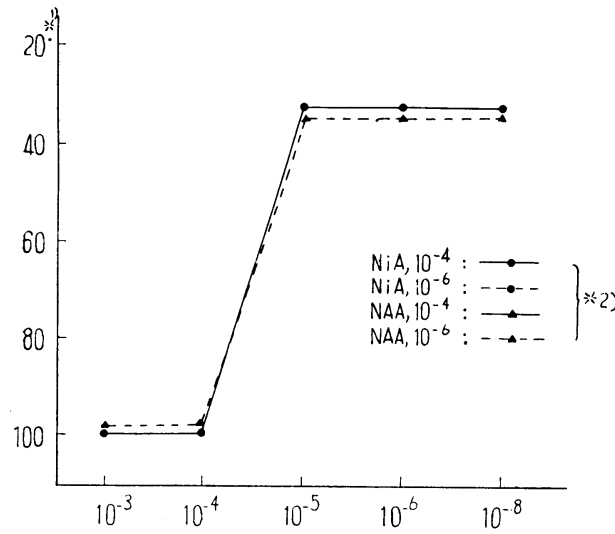

Molar concentration of Pyridine-3-sulfonic acid

*1) 縦軸は以下 Light Transmission Per Cent を示す

*2）以下の図に扣いて名特に示さぬ限り同様

しないと発育せず従つて基礎培地に $\mathrm{NiA} 10^{-4} \mathrm{M} /$ l 打 よで $10^{-6} \mathrm{M} / l$ 在添加あるいは $\mathrm{NA} \mathrm{A} 10^{-4} \mathrm{M} / l, \quad 10^{-6} \mathrm{M} / l$ を添加し更に Pyridine-3-sulfonic acid の $10^{-3} \sim 10^{-7} \mathrm{M} / l$ を同時添加してその発育に抢よぼす影響是しらべた。即 ち NiA, NAA いずれを添加した場合にも, また10-4, $10^{-6} \mathrm{M} / l$ いずれの濃度を用いた場合にも Pyridine-3- sul$\mathrm{f}_{\text {onic acid }}$ は $10^{-3}, 10^{-4} \mathrm{M} / l$ て菌の発育完全に阻止し $10^{-6}, 10^{-7} \mathrm{M} / l$ では何の影響も扢よ济さない。従つて Pyridine-3-sulfonic acid の発育阻止作用恃同時に存在す る NiA またはNAAによつて影響をこうむらない。48
困 3 Sh. sonnei (I) 標準株に対する Pyridine3-sulfonic acid の作用と NiA, NAA 添加の影響 24 hours Incubation

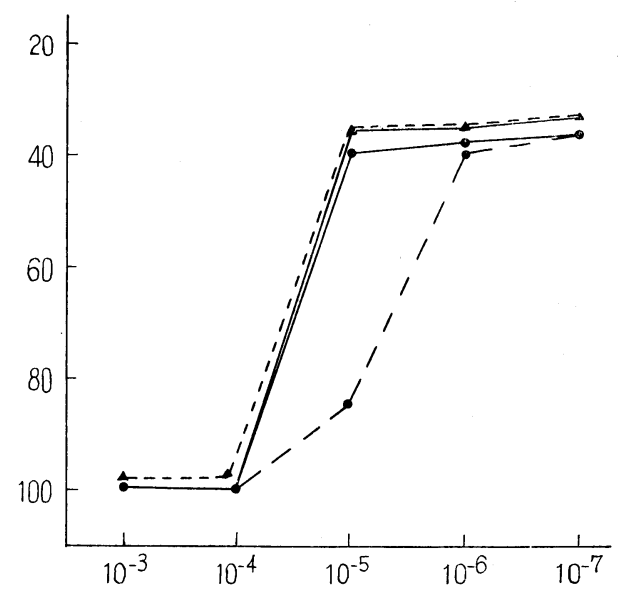

Molar concentration of Pyridine-3-sulfonic acid

図 4 Sh. sonnei (I) 標準株に対する $a$-Picolinic acid の作用と NiA, NAA 添加の影響

24 hours Incubation

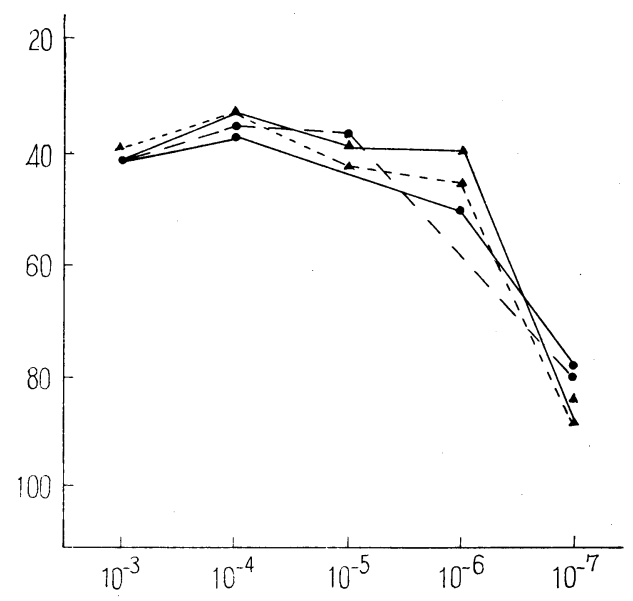

Molar Concentration of $\alpha$-Picolinic acid

時間培養時の所見は 24 時間培養時のそれと全く一致し た。Sh. Sonnei I 標準株 strain 1196 を用いた場合の Pyridine-3-sulfonic acid の作用结図 3 に示した。即ち分 離株の場合と同様に Pyridine-3-sulfonic acid $10^{-4} \mathrm{M} / l$ で発育を阻止し, $10^{-5} \mathrm{M} / l$ より濃度の少い時は 影響孛掞上ぼさない。ただ $\mathrm{NiA} 10^{-4} \mathrm{M} / l$ 同時添加時に は $\mathrm{NiA} 10^{-6} \mathrm{M} / l$ 同時添加時よりも Pyridine-3-sulfonic acid $10^{-5} \mathrm{M} / l$ 存在下ではわずかに良好な発育を示してい る。 
2）3-Acetyl pyridine の作用：Sh. sonnei I 標準株 の発育汇捛よ汸す 3-Acetyl pyridine の作用を上と同様 NiA,N A A 添加培地で検したが 3-Acetyl pyridine $\sim 10^{-7} \mathrm{M} / l$ の存在では NiA または NAAKょる本菌の 発育に何らの影響を与え得なかつた（成績省略。

3） $\alpha$-Picolinic acid の作用：Sh. sonnei I 標準株の 同一培地中に括仯る発育に扮よ济す $\boldsymbol{\alpha}$-Picolinic acidの 作用は図 4 亿要約した。即与24時間培養では NiA, NAA 添加の別, またはそれらの濃度によつて一定の影響を受 けないが $\alpha$-Picolinic acid 汸 $10^{-6}, 10^{-7} \mathrm{M} / l$ の濃度では 菌の発育に阻止的作用する。高濃度下ではかえつて影 響を与えない。しかしこれらの阻止作用は48時間培養で は見られない。

4）INAHの影響：Sh. sonnei I 分離株に対する INAHの作用を検討した。しかしINAH住 $10^{-3} \sim$ $10^{-7} \mathrm{M} / l$ の範囲では菌の発育は影響を受けない。（成績 省略)

5）類似化合物単独の作用：Sh. sonnei 標準株に対し $\tau$ Pyridine-3-sulfonic acid, 3-Acetyl pyridine, $\alpha$-Picolinic acid, INAH 学各単独に $10^{-3} \sim 10^{-8} \mathrm{M} / \mathrm{l}$ 添加すると Pyridine-3-sulfonic acid, $\boldsymbol{\alpha}$-Picolinic acid, INAH の 3 者で は菌は全く発育しないが 3 -Acetyl pyridine $10^{-6} \mathrm{M} / l$ 以 上になるとその濃度がこくなるにつれて菌も良好な発育 を示す。即与 3-Acetyl pyridine 以 NiA 活性をある程 度代用する。乙れらの成績は図 5 亿示した。

図 5 NiA 類似化合物の NiA 活性

(Sh. sonnei (I) 標準株, Strain 1196) 48 hours Incubation

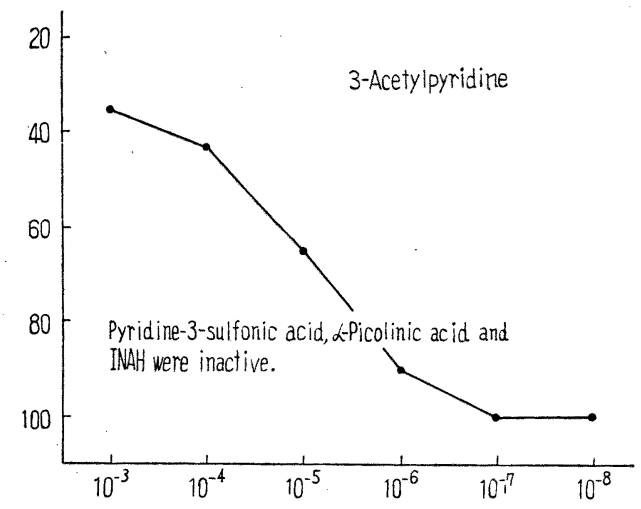

Molar Concentration of Niacin Analogous Tested

〔II〕 $\mathrm{NiA}$ を要求しない菌株に対する $\mathrm{NiA}$ 類似化合 物の作用

1）Sh. flexneri 3a の場合：Sh. flexneri 3a 分離株は
前報1)に示した様に全株共基碟培地のみで良好な発育を 示す。徒つて本菌では NiA 類似化合物の作用は基礎培 地のみに菌を培養した場合とこれにNiA なたはN A A 添加した場合の 2 つにわけて試験した。成績は図 $6 \mathrm{~A}$, B に示した。基礎培地の及の場合 $10^{-3} \sim 10^{-7} \mathrm{M} / l$ の濃度 範囲では 3-Acetyl pyridine, INAH, $\alpha$-Picolinic acid の 3

因 6 Sh. flexneri 3a（分醀株）の坦合 （A） NiA 類似化合物の作用（基磄培地のみの坦合） 48 hours Incubation

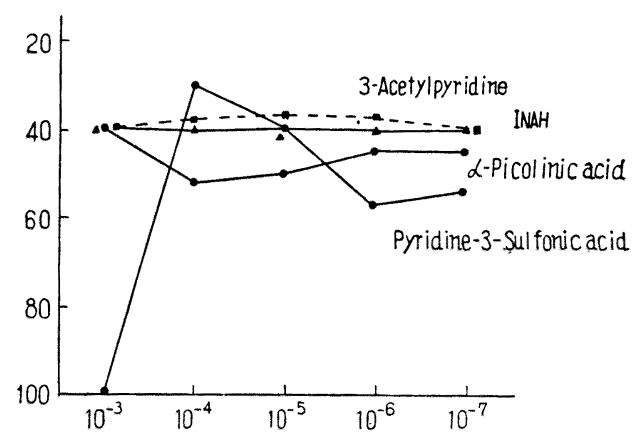

Molar Concentration of Three Niacin Analogous

(B) Pyridine-3-sulfonic acid の作用 (NiA 存在下)

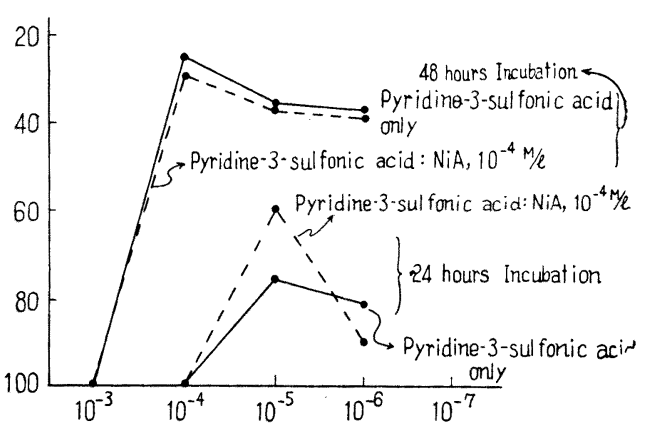

Molar Concentration of Pyridine-3-sulfonic acid

者は認め得る発育促進又は阻止作用を示さないが Pyridine-3-sulfonic acidのみは $10^{-3} \mathrm{M} / l$ でのみ完全発育阻止作 用を呈する。Pyridine-3-sulfonic acid 各等モルの NiA と同時に $10^{-3} \sim 10^{-7} \mathrm{M} / l$ 添加した場合は同図 B に示した 様に NiA は Pyridine-3-sulfonic acid の阻止作用を緩 和し得なかつた。

2）E. coli O-20の場合：4 種の類似化合物の $\mathrm{O}-20$ 標 準株に抢よ汭す影響について図7に示す成績を得た。い ずれも NiA, NAA を添加せず基碟培地中での成績であ る。即ち菌の発育の模様は Sh. flexneri 3a を用いた場 
図 7 Pyridine-3-sulfonic acid, a-Picolinic acid, 3-Acetylpyridine, INAH の $E$. coli $0-20$ に対する作用

\section{4 hours Incubation}

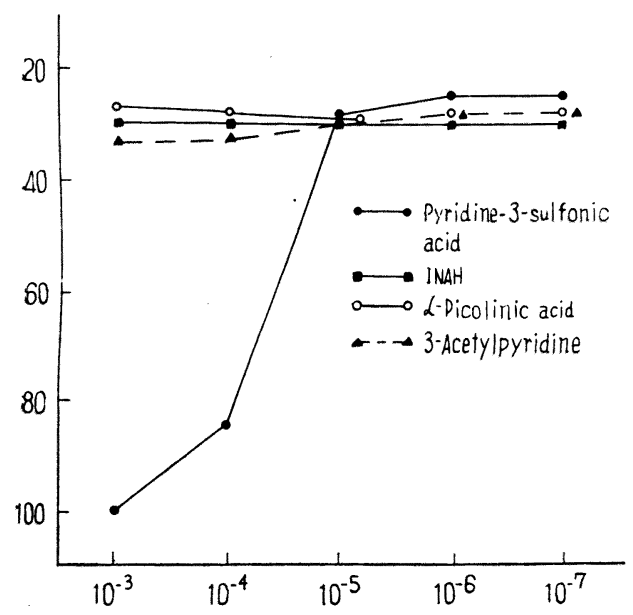

Molar Concentration of Niacin Analogous

合とほぶ等しく $\boldsymbol{\alpha}$-Picolinic acid，3-Acetyl pyridine, INAH の 3 者は菌の発育何らの影響を扣よ添さない。

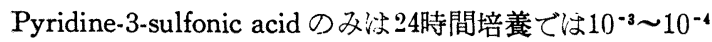
$\mathrm{M} / l$ の範囲で 48 時間培養では $10^{-3} \mathrm{M} / l$ に捛いてのみ発育 を阻止した。

\section{者宾}

$\mathrm{NiA}$ 類似化合物の赤㢉菌および大腸菌の発育に抢よ 添す影響について研究した。供試赤峲菌としては $\mathrm{NiA}$ 要求株として洨 Sh. sonnei I 亿属する菌株を, 非要求 株としては Sh. flexneri 3a 滥属する菌株をえらんだ。 Sh. sonnei I 化属与る供試菌纯 $\mathrm{NiA}$ または $\mathrm{NAA} 10^{-6}$ $\mathrm{M} / l$ 以上の濃度では 24 時間培養ですでに最高発育を示 す。即ち $\mathrm{NiA}$ を必須発高因子とする。使用した $\mathrm{NiA}$ 類似化合物として洨 Pyridine-3-sulfonic acid, 3-Acetyl pyridine, $\boldsymbol{\alpha}$-Picolinic acid, INAHの 4 種である。これ らのうち $\alpha$-Picolinic acid とINAHの2つは実験した 範囲の条件下で注赤㢉菌，大腸菌共汇発有它阻止せずま た NiA 活性も代用し得なかつた。ただ Sh. sonnei I

標準株の NiA, NAA 添加時に抢汀る発等が $\boldsymbol{\alpha}$-Picolinic acid の低濃度 $\left(10^{-6} \sim 10^{-7} \mathrm{M} /\right.$ l)でわ゙゙かに抑制される成 樍をえているが原因约現段階では説明しがたい。後述の 3-Acetyl pyridine の $\mathrm{NiA}$ 活性のむることょり みるこ $\mathrm{NiA}$ 活性济 3 位のカルボキシル基が重要な意味をもち

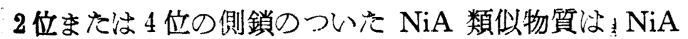

活性をもたなかつた。 $\mathrm{NiA}$ 代謝の時にも認め得べき影響 を与えぬものと推定される。

一方 3-Acetyl pyridine 纱供試菌の発育省阻止せず逆 にある程度 $\mathrm{NiA}$ 活性を示す。即与単独添加で $\mathrm{NiA}$ 要 求菌でをる Sh. sonnei I の発育を支持する。しかし

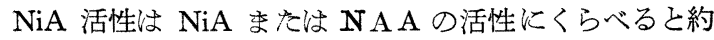
$1 / 10$ K相当し且つ Lagphase 浪長い。このこと缺3-Acetyl pyridine が生体内で招そらく NiA に転換した後に 活性をもつ様になることを意味する。

Pyridine-3-sulfonic acid の発育物質としての作用は古 くは McIlwain ${ }^{3)}$ の報告がある。今回の実験に扔いても Pyridine-3-sulfonic acid $10^{-3} \sim 10^{-4} \mathrm{M} / l$ の濃度では供 試した赤峲菌または大腸菌の発育を完全に阻止した。と のこと注 P A B A 類似化合物である Sulfanilic acid が 抗菌作用をもつ点よりもうなずける。ただ Pyridine-3sulfonic acid の赤㢉菌又は大腸菌汇対する発育阻止作用 は $\mathrm{NiA}$ または $\mathrm{NAA} 10^{-4} \mathrm{M} / l$ 又は $10^{-6} \mathrm{M} / l$ の添加で少

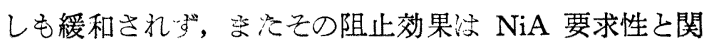
係がみられなかつた点よりとの物質が NiA の生合成ま たは NiA の利用を阻害するために抗菌力をもつかどう かについては不明である，NiAでは緩和し得ないがNiA より代謝上位の化合物即ち Pyridine nucleotide では緩 和するのではないかと考えブイヨン中での抗菌力もしら べたがやはり有効阻止濃度は $10^{-4} \mathrm{M} / l$ 以上でブイヨン成 分によつては影響はうけなかつた。とれらょり Pyridine3-sulfonic acid の阻止作用は NiA と競り合うのではな くむしろスルフォン酸基そのものの抗菌力も考える必要 があるのかす知れない。

\section{結論}

1) $\mathrm{NiA}$ 類似化合物 4 種即 5 3-Acetyl pyridine, Pyridine-3-sulfonic acid, $\boldsymbol{\alpha}$-Picolinic acid および I N$\mathrm{AH}$ の赤峲菌の発育に抢よ㳊す作用について研究した。

2）供試赤菽菌として蛙 $\mathrm{NiA}$ を必須発育因子とする 菌株の代表として Sh. sonnei に属する 2 株を, NiA 非 要求株即与基磁培地のみでよく発育する菌株の代表とし

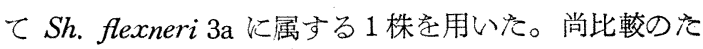
めE. coli 1 株も用いた。

3） $\boldsymbol{\alpha}$-Picolinic acid およびI N.A Hは共以被検囷株の 発育化何らの影響も扮上淩さ标かつ。

4) Pyridine-3-sulfonic acid 被検全菌株飞対し $10^{-3}$ $\sim 10^{-4} \mathrm{M} / l$ で発育を完全に阻止した。この阻止作用注 $\mathrm{NiA}$ 要求性乙関係なくまた $\mathrm{NiA}, \mathrm{NAA}$ 添加等では緩 和されなかつた。 
5) 3-Acetyl pyridine は $\mathrm{NiA}$ 要求菌の発育を支持し $\mathrm{NiA}$ 活性をある程度代用し得る成績を得た。

終にのぞみ本研究の機会を与えられ且つご校閲をたま わつを当研究所長芳野俊五博士に厚く和礼を申し上げま す。まを貴重な化合物を提供していただいた山口県立医 科大学微生物学教堂林良二教授に感謝の意を表します。

\section{引用交献}

1) 中山・ 川口・宇木 ・ 日本細菌学雑誌印刷中.
2) Woods, D. D. : Brit. J. Exp. Path., 21 : 74, 1940.

3) McIlwain, H. , Biochemistry and Chemotherapy, Nature, 151, 270, 1943.

4）林・中山・元木：第116回ビタミン B研究委員会 記事.

5) Davis, B. D. : Proc. Natl. Acad. Sci. U. S. 1949.

6) Davis, B. D. Mingioli, E. S. : J. Bact., 60 : 17, 1950. 